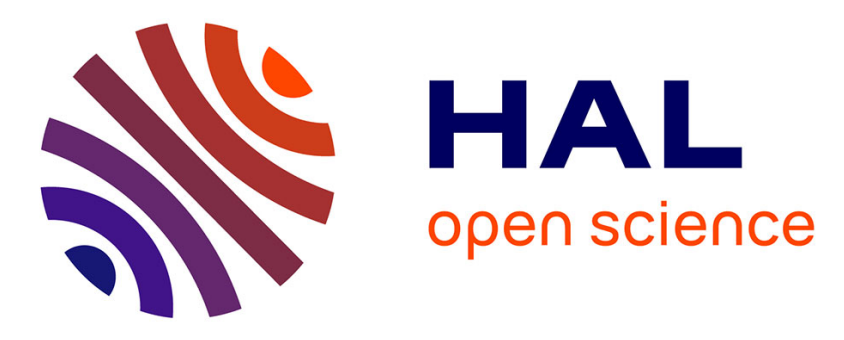

\title{
Nitrogen incorporation in Titan's tholins inferred by high resolution orbitrap mass spectrometry and gas chromatography-mass spectrometry
}

Thomas Gautier, Nathalie Carrasco, Isabelle Schmitz-Afonso, David Touboul, Cyril Szopa, Arnaud Buch, Pascal Pernot

\section{To cite this version:}

Thomas Gautier, Nathalie Carrasco, Isabelle Schmitz-Afonso, David Touboul, Cyril Szopa, et al.. Nitrogen incorporation in Titan's tholins inferred by high resolution orbitrap mass spectrometry and gas chromatography-mass spectrometry. Earth and Planetary Science Letters, 2014, 404, pp.33-42. 10.1016/j.epsl.2014.07.011 . hal-01056129

\section{HAL Id: hal-01056129 \\ https://hal.science/hal-01056129}

Submitted on 14 Jan 2022

HAL is a multi-disciplinary open access archive for the deposit and dissemination of scientific research documents, whether they are published or not. The documents may come from teaching and research institutions in France or abroad, or from public or private research centers.
L'archive ouverte pluridisciplinaire HAL, est destinée au dépôt et à la diffusion de documents scientifiques de niveau recherche, publiés ou non, émanant des établissements d'enseignement et de recherche français ou étrangers, des laboratoires publics ou privés.

\section{(c) (1) $\$$}

Distributed under a Creative Commons Attribution - NonCommerciall 4.0 International 


\title{
Nitrogen incorporation in Titan's tholins inferred by high resolution orbitrap mass spectrometry and gas chromatography-mass spectrometry
}

\author{
Thomas Gautier ${ }^{\mathrm{a}, *}$, Nathalie Carrasco ${ }^{\mathrm{a}, \mathrm{b}}$, Isabelle Schmitz-Afonso ${ }^{\mathrm{c}}$, David Touboul ${ }^{\mathrm{c}}$, \\ Cyril Szopa ${ }^{\mathrm{a}}$, Arnaud Buch ${ }^{\mathrm{d}}$, Pascal Pernot ${ }^{\mathrm{e}}$ \\ a Université de Versailles St Quentin, LATMOS, UPMC Univ. Paris 6, CNRS, 11 bvd d'Alembert, 78280 Guyancourt, France \\ ${ }^{\mathrm{b}}$ Insitut Universitaire de France, 103 Bvd St-Michel, 75005 Paris, France \\ c Centre de Recherche de Gif, Institut de Chimie des Substances Naturelles, CNRS, avenue de la Terrasse 91198, Gif-sur-Yvette cedex, France \\ d LGPM, Ecole Centrale de Paris, Grande voie des Vignes, 92295 Chatenay-Malabry cedex, France \\ e Laboratoire de Chimie Physique, UMR 8000, CNRS, Université Paris-Sud 11, 91405 Orsay cedex, France
}

\begin{abstract}
Influx of solar photons and heavy charged particles from Saturn's magnetosphere on Titan's atmosphere - mainly comprised of methane and nitrogen - induce an intense organic photochemistry which leads to the formation of a large amount of aerosols in suspension in the atmosphere. In order to infer the role of nitrogen in aerosol formation processes we produced laboratory analogs of Titan's aerosols. In this work, we compare the composition of different analogs by using high resolution mass spectrometry and propose an additional study using gas-chromatography coupled to mass-spectrometry for a new kind of analog produced by polymerization of cryogenically trapped gaseous neutral species. The comparison of these materials emphasizes the importance of ion chemistry processes for the inclusion of nitrogen in molecules constituting Titan's tholins. A statistical approach is also used for the treatment of high resolution mass spectra of these highly complex organic materials. This method allows distinguishing molecular families that can be reconstructed by an ideal copolymer. We investigate several copolymer reconstructions, and we suggest that an $\mathrm{HCN}$ (or $\mathrm{CH}_{3} \mathrm{CN}$ ) $/ \mathrm{C}_{2} \mathrm{H}_{4}$ based copolymer agrees well with the polymeric structure of tholins produced with $5 \%$ of methane in nitrogen.
\end{abstract}

\section{Introduction}

Titan, the biggest satellite of Saturn, presents a dense atmosphere mainly composed of molecular nitrogen and methane. Solar irradiation and electrically charged particles coming from Saturn's magnetosphere induce chemical reactions in the atmosphere of Ti$\tan$ that lead to the formation of an organic haze veil surrounding Titan.

These organic aerosols are of high interest due to both the deep impact of their presence on atmospheric processes (McKay et al., 1991) and their organic structure. Indeed, aerosols are composed of nitrogen, carbon and hydrogen, and thus probably include molecules of high astrobiological interest. For example, the presence of molecules such as adenine was reported in a recent study

\footnotetext{
* Corresponding author. Tel.: +331 802852 77; fax: +33 180285290 E-mail address: thomas.gautier@latmos.ipsl.fr (T. Gautier).
}

performed on aerosol analogues produced in the laboratory (Hörst et al., 2012).

Even if the Cassini/Huygens (NASA/ESA) space mission provided information on these aerosols - either by in-situ measurements done with the Huygens descent probe or by spectroscopic probing with the Cassini spacecraft during the fly-by of the satellite - their physical and chemical nature remain mostly unknown (Coll et al., 2013; Israel et al., 2005; Waite et al., 2007; West et al., 2014).

In order to better understand and constrain their composition and formation pathways, it is of great interest to study laboratory analogues, the so called "tholins", to support observations on Titan's aerosols (Cable et al., 2012; Coll et al., 2013).

Different laboratory experiments are devoted to producing Titan's tholins, including the PAMPRE device developed in LATMOS (France). It is a radiofrequency capacitively coupled plasma (RFCCP) allowing the production of a large quantity of tholins grown in volume, due to the particular configuration of the plasma discharge (Szopa et al., 2006). These samples produced in volume 
in the plasma discharge will be called p-tholins in the present study.

Previous studies have been performed on chemical composition of tholins produced in plasma experiments and are comparable with our p-tholins. Elemental analysis (Imanaka et al., 2004; Sciamma-O'Brien et al., 2010) provided a first chemical information on the $\mathrm{C} / \mathrm{N} / \mathrm{H}$ ratios in tholins. These analyses are not sufficient to determine their detailed molecular composition. Consequently, other types of chemical analyses have been used such as infrared spectroscopy (Gautier et al., 2012; Imanaka et al., 2012), X-ray photoelectron spectroscopy (Ruiz-Bermejo et al., 2009, 2008; Tran et al., 2003), chromatographic techniques such as gas chromatography-mass spectrometry (GC-MS) (He and Smith, 2013); pyrolysis-GC-MS or high performance liquid chromatography (Coll et al., 2013; Ruiz-Bermejo et al., 2008), nuclear magnetic resonance spectroscopy (Derenne et al., 2012; He et al., 2012a, 2012b) and high resolution mass spectrometry, based on either orbitrap (Hörst et al., 2012; Pernot et al., 2010) or Fourier transform ion cyclotron resonance (Somogyi et al., 2012).

These analyses confirmed that tholins are not only made of hydrocarbons but also include a large amount of nitrogen which contributes to chemical functional groups of interest for astrobiology, such as amines or nitriles. A polymeric growth of tholins has already been proposed (Pernot et al., 2010; Carrasco et al., 2009). This hypothesis is discussed in the recent review by Cable et al. (2012).

In addition to p-tholins, we also studied an intermediate material, the so called c-tholins, also generated with the PAMPRE experiment, in a cryogenic trap. C-tholins are formed by the reaction of neutral gases condensed at the reactor outlet in a cold trap maintained approximately at the liquid nitrogen temperature (Gautier et al., 2011). Discussed in details in Gautier et al. (2011), the major gas products trapped were found to be qualitatively in agreement with the main species photoproduced in Titan's atmosphere. C-tholins are then formed in the cold trap when it is warmed up to the room temperature. It might be interesting to draw closer the c-tholins formation with the evolution of Titan's aerosols in the lower atmosphere. Indeed, at low altitude, some reactive gases such as $\mathrm{HCN}$ or $\mathrm{CH}_{3} \mathrm{CN}$ can condensate on the surface of aerosols (Lavvas et al., 2011; Anderson and Samuelson, 2011). As a result, chemical reactions can be induced in this condensed phase at the surface of aerosols. Reasonably, we can make the assumption that this chemistry would lead to the formation of an organic material possibly similar to the c-tholins.

In order to infer the influence of ion chemistry on tholins composition, we present here a comparative study of p-tholins (produced in the plasma, with ion chemistry) and c-tholins (produced outside a plasma). C-tholins are formed spontaneously inside the cryogenic trap isolated from the reactor, when it is warmed up to room temperature. The trapped species react then to form a brownish residue, the c-tholins. The investigations on the chemical patterns in p-tholins molecular structure are performed using high resolution mass spectrometry with the data analysis proposed by Pernot et al. (2010). We also use GC-MS analyses to identify specific components of the unknown c-tholins material.

\section{Experimental set-up and protocol}

\subsection{PAMPRE experiment}

A detailed description of the experimental setup configuration used in this study can be found in previous publications (Gautier et al., 2011; Szopa et al., 2006). Here we briefly remind the main characteristics of the setup. The gaseous mixture used in the setup is a nitrogen-methane mixture, containing from 1 to $10 \% \mathrm{CH}_{4}$, simulating Titan's main atmospheric composition (Niemann et al.,
2005; Waite et al., 2007). The reactor is a cylindrical stainless steel chamber. The RF-CCP discharge is established thanks to an $\mathrm{RF} 13.56 \mathrm{MHz}$ frequency generator. The gas mixture is injected as a continuous flow through the polarized electrode and extracted by a vacuum pump. This design allows the flow to be uniform in the reactor.

A cold trap, approximately brought to the liquid nitrogen temperature, can be set on the gas outlet of the reactor. Gas pumped from the reactor passes through this trap where products coming from the reactive mixture can condense, depending on the pressure and temperature. With this set-up (for c-tholins production experiments), the pressure in the PAMPRE reactor up to $1.7 \pm 0.1$ mbar instead of $0.9 \pm 0.1 \mathrm{mbar}$ in standard conditions due to the reduced pumping efficiency induced by the cold trap. At the end of an experimental run, the trap is isolated from the reactor with a valve.

\subsection{Samples produced in the plasma (p-tholins) and in the cryogenic trap (c-tholins)}

The experiments were performed with two $\mathrm{N}_{2} / \mathrm{CH}_{4}$ mixtures containing 1 and $5 \% \mathrm{CH}_{4}$, respectively.

P-tholins samples were accumulated during two days in a glass vessel surrounding the reactive plasma and then collected into vials such as presented in Hadamcik et al. (2013).

C-tholins are produced in the cryogenic trap where gas produced in the plasma discharge are trapped for $2 \mathrm{~h}$. When the trap is warmed up to the room temperature, a part of the condensed gases evaporates whereas the other part is involved in chemical reactions which generate c-tholins at the bottom of the cold trap. These c-tholins are formed without involving ionic chemistry and are thus supposed to come from direct polymerization of the gaseous products in the cold trap, or by reactions in the condensed phase in the cold trap. Analysis of the gaseous phase has been reported in a previous study (Gautier et al., 2011), showing that it is mainly composed of nitriles and hydrocarbons.

Fig. SI 1 (supplementary information) shows the formation of the c-tholins in the cold trap when warmed up to room temperature.

\subsection{Sample treatment for mass spectrometric analyzes}

For mass spectrometric analysis, p-tholins were first dissolved in methanol (HPLC grade, Baker) at a concentration of $1 \mathrm{mg} \mathrm{mL}^{-1}$, then mixed thoroughly and the resulting solution was filtered through a PTFE $0.2 \mu \mathrm{m}$ membrane. The choice of methanol as the solvent is consistent with a previous study on p-tholins solubility (Carrasco et al., 2009). C-tholins were also dissolved in methanol for analysis. It can be noticed that p-tholins are poorly soluble in methanol ( $\sim 30 \%$ solubility) whereas the c-tholins are totally soluble. The samples were then infused in an ElectroSpray Ionization (ESI) Source in $\mathrm{MeOH} /$ water $(50 / 50, \mathrm{~V} / \mathrm{V}$ ) at a flow rate of $10 \mu \mathrm{L} \mathrm{min}^{-1}$. Water was chosen to improve ionization efficiency. Since tholins degradation in liquid environment occurs on time scales varying from a few hours to a few weeks (Neish et al., 2009; Poch et al., 2012), samples were dissolved a few minutes before their analysis in order to prevent tholins structure alteration from interaction with the solvent.

The resulting ions were then analyzed using a high resolution mass spectrometer, with a hybrid linear trap/orbitrap analyzer (LTQ-Orbitrap, Thermo Scientific). Acquisition parameters in positive ion mode were: needle voltage $4.5 \mathrm{kV}$, capillary temperature $275^{\circ} \mathrm{C}$, capillary voltage $25 \mathrm{~V}$, tube lens voltage $65 \mathrm{~V}$ and sheath gas flow rate 12 arbitrary unit (a.u.). In negative ion mode, parameters were: needle voltage $3 \mathrm{kV}$, capillary temperature $275^{\circ} \mathrm{C}$, 
capillary voltage $-15 \mathrm{~V}$, tube lens voltage $-45 \mathrm{~V}$ and sheath gas flow rate 12 a.u.

The mass spectrometer was externally calibrated using caffeine, MRFA (met-arg-phe-ala) peptide mix and Ultramark 1621 allowing a mass precision below $2 \mathrm{ppm}$. Data were acquired between $\mathrm{m} / z$ 50 and $\mathrm{m} / \mathrm{z} 800$ and integrated on several hundred scans (usually between 350 and 400). Data were acquired with a mass resolution fixed at 100000 for an ion at $m / z 450$. The experimental resolution $(\Delta \mathrm{m} / \mathrm{m})$ was determined to be $\sim 200000$ at $m / z 150$. As a first approach for data treatment, we only considered protonation $\left([\mathrm{M}+\mathrm{H}]^{+}\right.$species, positive ion mode $)$and deprotonation $\left([\mathrm{M}-\mathrm{H}]^{-}\right.$ species, negative ion mode) reactions. Data were processed using XCalibur 2.0 software and its peak attribution function. In order to ensure unambiguous attribution of the species, the data treatment was limited up to $m / z$ 400. Attribution parameters were: maximum authorized deviation of $5 \mathrm{ppm}$ to ensure possible attribution for species of low masses $(m / z<120)$, maximum carbon atoms number of 60 , maximum nitrogen atoms number of 60 , maximum hydrogen atoms number of 100 . The last three parameters were set to be sure to possibly attribute all existing peaks in the sample. Nitrogen rule was used and charge was set to +1 (and -1 for analysis in negative ion mode). In order to take into account possible oxygen contamination (in the reactor due to residual gases after pumping or when sample is exposed to air) two oxygen atoms were also allowed in the peak attribution. Similar to the study of Pernot et al. (2010), we focused this study on the non-oxygenated fraction of the sample. All oxygenated peaks were thus removed from the spectra before statistical analysis.

The c-tholins sample produced with $4 \%$ of methane was also analyzed using GC-MS. The first analysis is a direct injection into the chromatographer after dilution. A second analysis is performed on the c-tholins diluted in methanol and using derivatization to enhance the volatility of refractory compounds. The two derivatization agents used for this work are DMF-DMA (N,N-dimethylformamide dimethylacetal) and MTBSTFA ( $\mathrm{N}$-( $t$-butyldimethylsilyl)-N-methyltrifluoroacetamide). DMF-DMA is an alkylation agent generally used for derivatization of amines (primary and secondary) and carboxylic acids (Freissinet et al., 2010; Meierhenrich et al., 2001). MTBSTFA is a silylation (addition of $-\mathrm{Si}\left(\mathrm{CH}_{3}\right)_{2}-\mathrm{C}\left(\mathrm{CH}_{3}\right)_{3}$ fragment) agent commonly used for amino acid derivatization (Buch et al., 2009).

For direct injection c-tholins are diluted in dichloromethane and are diluted in methanol for the derivatization process. C-tholins appear to be totally soluble in both solvents, which is not the case for p-tholins (Carrasco et al., 2009).

The column used for this analysis is a CP-Chirasil-Dex CB(Varian), $L=30 \mathrm{~m}, \mathrm{ID}=0.25 \mathrm{~mm}, \mathrm{df}=0.53 \mu \mathrm{m}$. The injector temperature is set at $270{ }^{\circ} \mathrm{C}$, helium flow rate at $1 \mathrm{mLmin}^{-1}$, split at $1 / 20$. Temperature ramp is: $34^{\circ} \mathrm{C}$ for $5 \mathrm{~min}$, then $5^{\circ} \mathrm{C} \mathrm{min}-1$ up to $190^{\circ} \mathrm{C}$ and then isotherm at $190^{\circ} \mathrm{C}$ for $5 \mathrm{~min}$.

\section{Results and discussion}

\subsection{Influence of methane percentage on p-tholins composition}

In addition to the analysis of the data for p-tholins produced at $1 \%$ and $5 \%$ of methane in nitrogen, we validate our data treatment by reanalyzing data acquired for a previous study (Pernot et al., 2010) on p-tholins produced under the same experimental conditions with $2 \%$ and $10 \%$ of methane in nitrogen respectively.

Fig. 1 presents the Orbitrap mass spectra of four different ptholins samples produced with $1 \%, 2 \%, 5 \%$ and $10 \%$ of methane in the gas mixture. Two kinds of structures are visible on these spectra: first, intense and isolated peaks (mainly at $m / z<150$ ); second, regularly spaced clusters generally observed when analyzing a polymeric material.
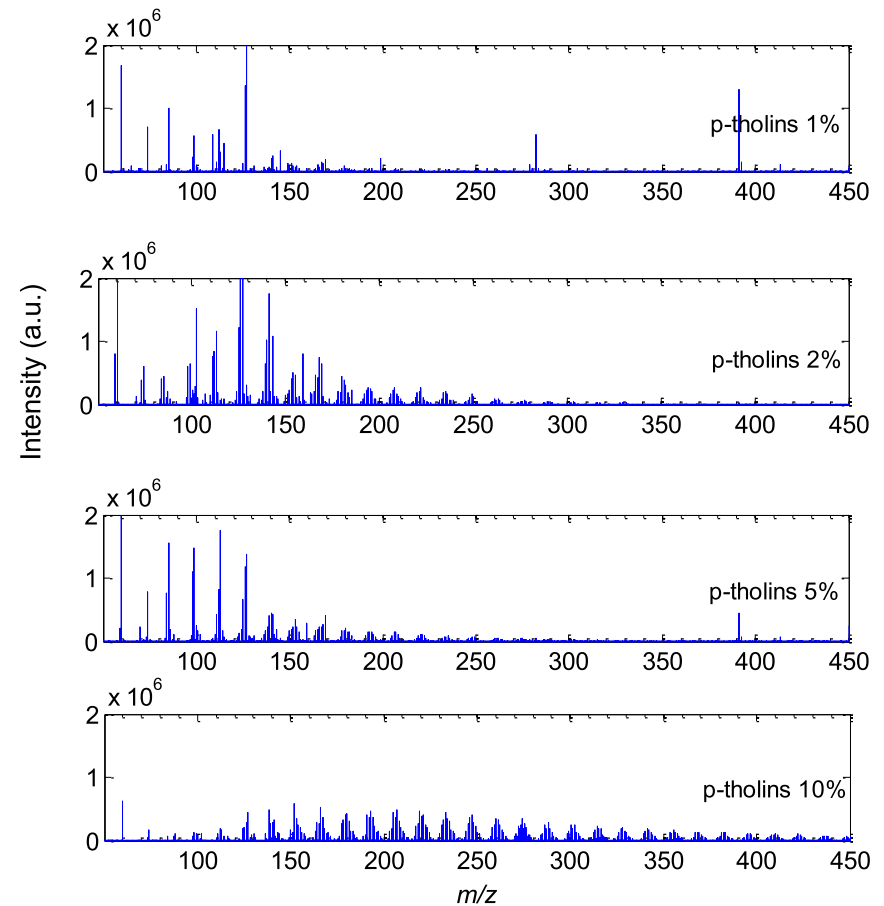

Fig. 1. Orbitrap mass spectra in positive ion mode of p-tholins samples produced with $1 \%, 2 \%, 5 \%$ and $10 \%$ of methane. Spectra at $2 \%$ and $10 \%$ are the same spectra that were analyzed in Pernot et al. (2010). To enhance visibility of the spectra intensity is limited to $2 \mathrm{e} 6$, some peaks in the $2 \%$ and $5 \%$ spectra extend slightly above this limit.

The cluster structure is representative of almost all the material at high methane percentage, whereas the first structure is predominant in spectra of p-tholins produced with 1,2 or $5 \%$ of methane.

These light species are mainly located in the right wing of the Van Krevelen diagram (cf. Fig. 3), which means compounds containing a large amount of nitrogen ( $\mathrm{N} / \mathrm{C}$ ratio higher than 1.5 ). These light but nitrogen-rich species are therefore less incorporated in samples produced at $10 \%$ of methane. The decrease of nitrogen content in p-tholins with increase of methane percentage, has also been observed at a global scale, by elemental analysis (Sciamma-O'Brien et al., 2010) and by infrared spectroscopy, studying the evolution of aliphatic carbon/amines bands ratio (Gautier et al., 2012).

Fig. 2 presents a close up of Fig. 1 centered on the peaks detected around $m / z$ 127. Two major ion peaks are detected at $m / z 127.0725(\Delta m=-1.31 \mathrm{ppm})$ and $m / z 127.0977(\Delta m=$ $-1.30 \mathrm{ppm}$ ), respectively attributed to $\mathrm{C}_{3} \mathrm{H}_{6} \mathrm{~N}_{6}$ (possibly melamine) and $\mathrm{C}_{5} \mathrm{H}_{10} \mathrm{~N}_{4}$.

As shown in Fig. 2, there is an inversion in the relative intensity of these two peaks when increasing the methane percentage. $\mathrm{C}_{3} \mathrm{H}_{6} \mathrm{~N}_{6}$ is more predominant for p-tholins produced with 1,2 and $5 \%$ of methane whereas for $10 \%, \mathrm{C}_{5} \mathrm{H}_{10} \mathrm{~N}_{4}$ is the major compound exhibiting less nitrogen and more carbon atoms. This is consistent with the increase of global nitrogen content in p-tholins when methane percentage decreases as observed in the elemental analyses (Sciamma-O'Brien et al., 2010). At an intermediate percentage (5\%), both peaks have similar intensities. This phenomenon can be observed in all predominant clusters between $m / z 70$ and $m / z 300$.

In order to compare the samples, Van Krevelen diagrams adapted for nitrogen bearing molecules can be plotted (Imanaka and Smith, 2007; Pernot et al., 2010; Somogyi et al., 2012). These diagrams are scatter plots of the $\mathrm{H} / \mathrm{C}$ ratio as a function of $\mathrm{N} / \mathrm{C}$ ratio for detected molecules, as shown in Fig. 3. 

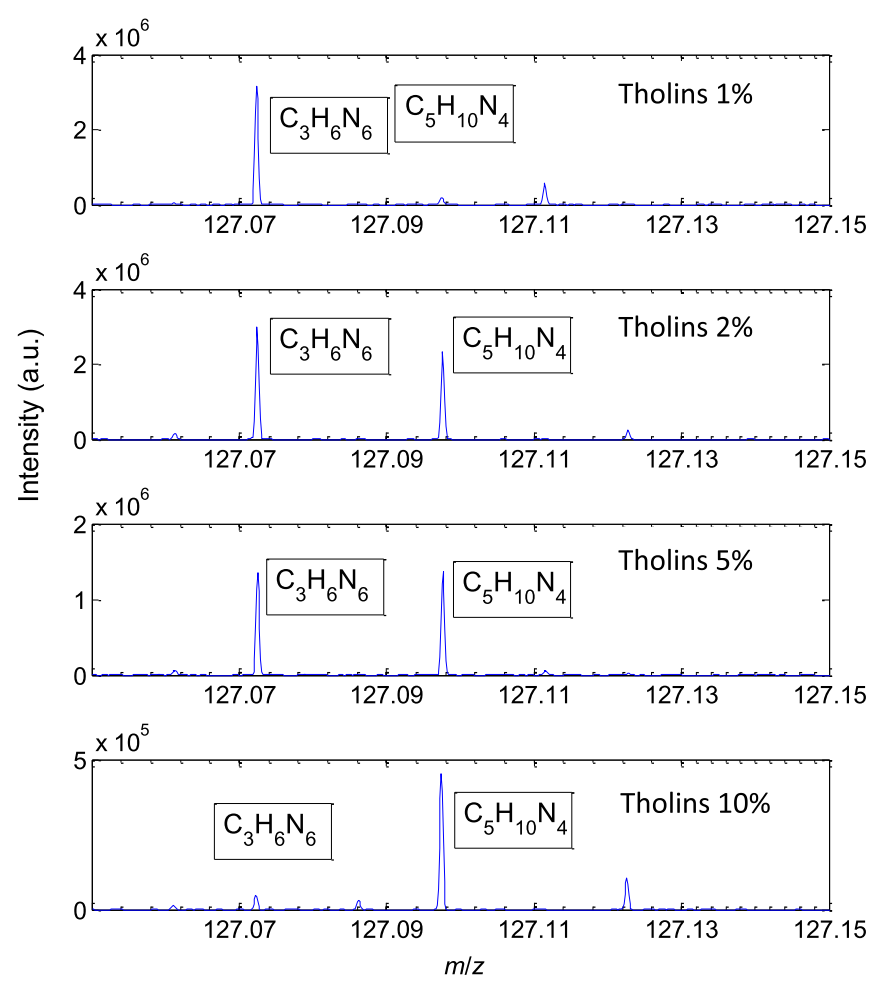

Fig. 2. Close-up of Fig. 1 around $m / z 127$ for each p-tholins sample.

In the 2D Van Krevelen diagrams, the visible linear alignments of structures cannot be directly linked to the polymer structure but only reflects the possible combinations for $\mathrm{C}_{X} \mathrm{H}_{Y} \mathrm{~N}_{Z}$ molecules. These combinations are limited to a compositional space defined by all combinations of carbon, nitrogen and hydrogen atoms in agreement with the nitrogen rule. The regular patterns observed in a standard 2D Van Krevelen diagram only reflect the intrinsic order of the compositional space (Hertkorn et al., 2008).
The first visible phenomenon in Fig. 3 is a decrease in the number of nitrogen bearing species of p-tholins observed when methane percentage increases. This is indicated by the depletion of the right "wing" (i.e. N/C > 1) of the diagram when the methane percentage increases, correlated with an increase of the density of the detected compounds with low N/C and $\mathrm{H} / \mathrm{C}$ ratios $(\mathrm{N} / \mathrm{C}<$ 0.5 and $\mathrm{H} / \mathrm{C}<2$ ). The latter may be linked to an increase of unsaturated hydrocarbons content in p-tholins, recently observed by Nuclear Magnetic Resonance (NMR) (Derenne et al., 2012).

A second effect visible in all p-tholins samples is that red and violet dots (high masses ions, $m / z>350$ ) are much more concentrated than yellow and orange (low masses ions) which are dispersed all over the diagram. This means that the species distribution tends to concentrate around specific values at high masses.

\subsection{Polymeric structure of $p$-tholins}

A modified 3D Van Krevelen diagram, with addition of $\ln (m / z)$ as a third dimension (Pernot et al., 2010), is visible in Fig. 4 for p-tholins produced with $5 \%$ of methane.

From Fig. 4, it is clear that a convergence of the distribution occurs when $\mathrm{m} / \mathrm{z}$ increases. This would mean that after enough polymerization steps, the material composition tends toward average ratios of $\mathrm{H} / \mathrm{C}=1.5$ and $\mathrm{N} / \mathrm{C}=0.5$, i.e. an ideal co-polymer with an average formula of $\left(\mathrm{C}_{2} \mathrm{H}_{3} \mathrm{~N}\right)_{n}$.

Fig. 4 also highlights that the molecules are organized among separated families distributed on different plans. In order to infer the most parsimonious polymeric representation of p-tholins, we extended the method proposed by Pernot et al. (2010), by testing a comprehensive set of monomeric bases. All detected molecules $\mathrm{C}_{x} \mathrm{H}_{y} \mathrm{~N}_{z}$ can hypothetically be formed by two fragments, for example $\mathrm{CH}_{2}$ and $\mathrm{HCN}$, plus a residue of carbon atoms: $\alpha$. Then, each molecule detected in the mass spectrum can be defined as $\mathrm{C} \alpha-\left(\mathrm{CH}_{2}\right)_{m}-(\mathrm{HCN})_{n}$ where:

$-n$ is the number of nitrogen atoms, systematically attributed to HCN units;

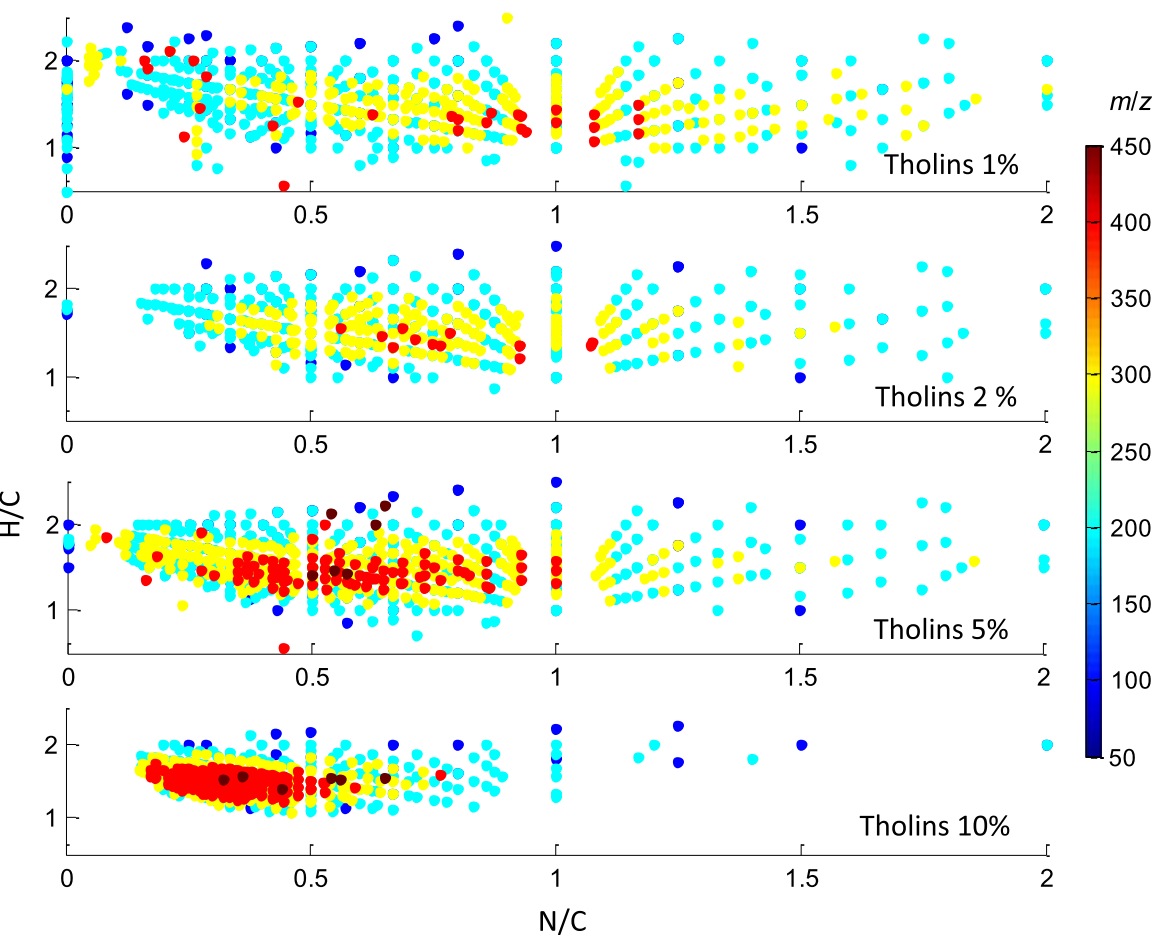

Fig. 3. Van Krevelen representation of p-tholins formed with $1 \%, 2 \%, 5 \%$ and $10 \%$ of methane. Colors of the dots represent the mass of the peak. 


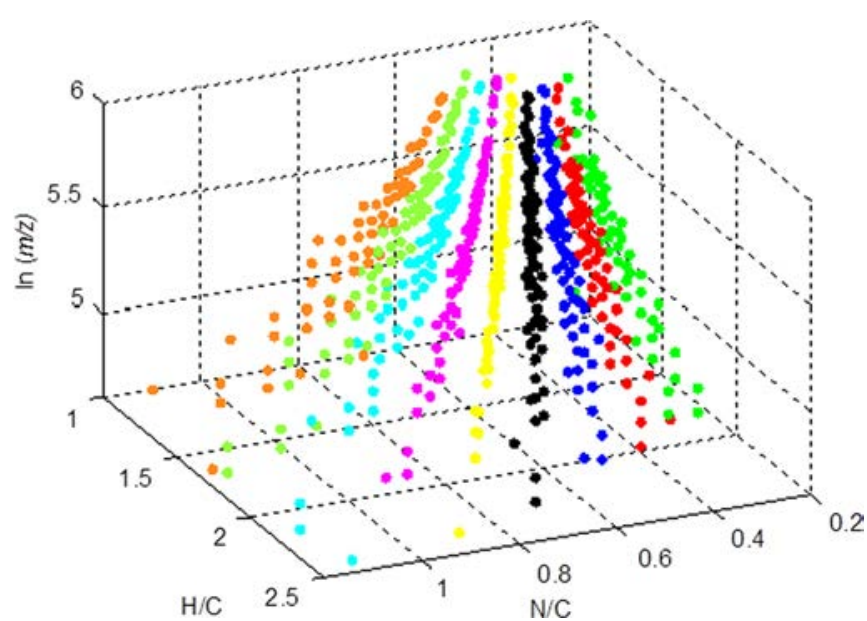

Fig. 4. 3D Van Krevelen diagram of p-tholins 5\%. Each color correspond to a plan defined by an $\alpha$ value within the $\mathrm{HCN} / \mathrm{CH}_{2}$ monomer basis (cf. part 3.2). The $\alpha=-5$ central plan is in yellow and negative and positive $\alpha$ values are located symmetrically around this central plan. (For interpretation of the references to color in this figure legend, the reader is referred to the web version of this article.)

$-m=(\mathrm{H}-\mathrm{N}) / 2$ considering that all $\mathrm{H}$ atoms but in $(\mathrm{HCN})_{n}$ belongs to $\mathrm{CH}_{2} . \mathrm{H}$ and $\mathrm{N}$ are respectively the number of hydrogen atoms and nitrogen atoms detected in a molecule;

$-\alpha$ is the number of carbon atoms completing the pure copolymer, thus $\alpha=\mathrm{C}-(\mathrm{H}+\mathrm{N}) / 2$. It is used to discriminate between families of compounds.

The formulae for $n, m$ and $\alpha$ has to be adapted to different base choices. Here we tested several alternative bases to determine which one provides the purest and most parsimonious representation of the material. Two bases, $\mathrm{HCN} / \mathrm{CH}_{2}$ and $\mathrm{HC}_{3} \mathrm{~N} / \mathrm{C}_{2} \mathrm{H}_{2}$ were used to validate the process proposed in Pernot et al. (2010). We also studied the following base pairs: $\mathrm{HCN} / \mathrm{C}_{2} \mathrm{H}_{2} ; \mathrm{HCN} / \mathrm{C}_{2} \mathrm{H}_{4}$; $\mathrm{HCN} / \mathrm{C}_{2} \mathrm{H}_{6} ; \mathrm{CH}_{3} \mathrm{CN} / \mathrm{CH}_{2} ; \mathrm{CH}_{3} \mathrm{CN} / \mathrm{C}_{2} \mathrm{H}_{2} ; \mathrm{CH}_{3} \mathrm{CN} / \mathrm{C}_{2} \mathrm{H}_{4} ; \mathrm{CH}_{3} \mathrm{CN} / \mathrm{C}_{2} \mathrm{H}_{6}$; $\mathrm{CH}_{2} \mathrm{NH} / \mathrm{CH}_{2} ; \mathrm{CH}_{2} \mathrm{NH} / \mathrm{C}_{2} \mathrm{H}_{2}$ and $\mathrm{NH}_{3} / \mathrm{C}_{2} \mathrm{H}_{4}$.
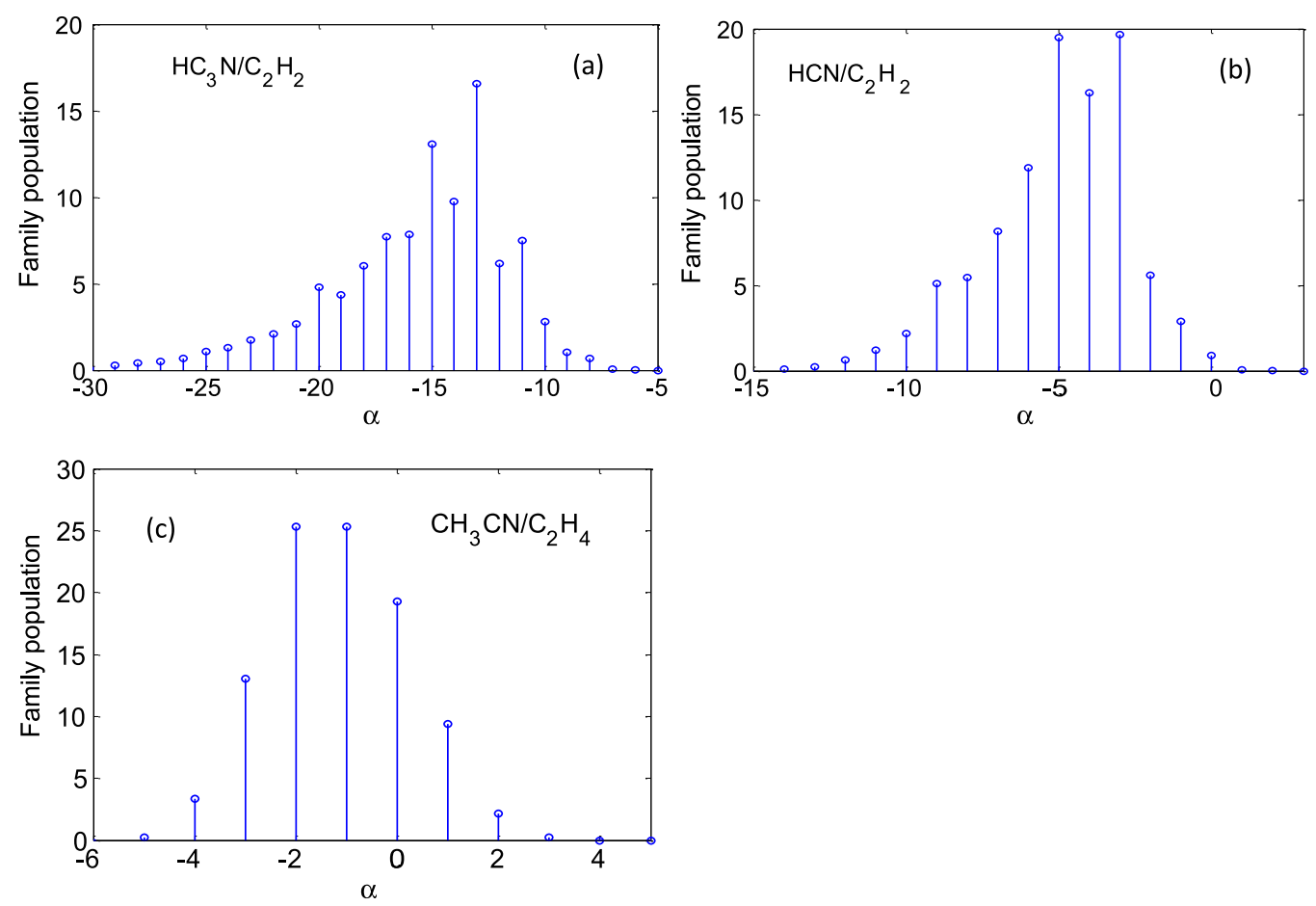

The distribution of the families, i.e. the number of families used to describe the whole material and the global intensity of the family (equal to the normalized sum of all peaks belonging to the family) was studied for each base. An example of the distribution for three different bases $\left(\mathrm{HC}_{3} \mathrm{~N} / \mathrm{C}_{2} \mathrm{H}_{2} ; \mathrm{HCN} / \mathrm{C}_{2} \mathrm{H}_{2} ; \mathrm{CH}_{3} \mathrm{CN} / \mathrm{C}_{2} \mathrm{H}_{4}\right)$ is given in Fig. 5.

We can see on Fig. 5 that the choice of the fragments influences the $\alpha$ distribution. It can be more or less centered on 0 and wide, defining two ranking criteria for the distribution:

- Based on the minimum of statistical entropy principal, we consider that a narrow distribution represents the sample better than a wide one.

- For two distribution of the same width, the one the most centered on $\alpha=0$ (i.e. which requires the less carbon atom compensation) is considered as the best.

The whole set of distributions represented by blue dots is summarized in Fig. 6. The size of the dot is proportional to the number of families used to describe the polymer, and the color of the dot is linked to the position of the distribution relatively to the $\alpha=0$ family.

In a general way, we prefer the narrowest distribution, as it provides the most parsimonious description of the sample (corresponding to the minimum of statistical entropy). For two distributions of the equal width, the one with the smallest absolute value of alpha is preferred, as it requires less carbon compensation.

For the hydrocarbons patterns, it seems that $\mathrm{CH}_{2}$ and $\mathrm{C}_{2} \mathrm{H}_{4}$ (which are statistically equivalent for this representation) present systematically better polymer reconstruction than $\mathrm{C}_{2} \mathrm{H}_{2}$ and $\mathrm{C}_{2} \mathrm{H}_{6}$ when used with nitriles as nitrogenous compounds. This could mean that the hydrocarbons needed for p-tholins initiation should not be highly unsaturated, as previously suggested (Kaiser and Mebel, 2012). Another possible explanation could be that tholins indeed grow through either unsaturated (such as $\mathrm{C}_{2} \mathrm{H}_{2}$ ) or totally saturated (such as $\mathrm{C}_{2} \mathrm{H}_{6}$ ) materials, and then either gain or loss hydrogen atoms by further chemistry in the reactive medium (Sekine et al., 2008; Gautier et al., 2014).

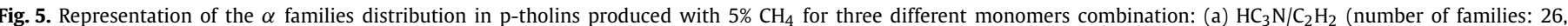
distribution maximum: -13 ); (b) $\mathrm{HCN} / \mathrm{C}_{2} \mathrm{H}_{2}$ (number of families: 16 , distribution center: -5 ); (c) $\mathrm{CH}_{3} \mathrm{CN}_{2} / \mathrm{C}_{2} \mathrm{H}_{4}$ (number of families: 8 , distribution center: -1 ). 


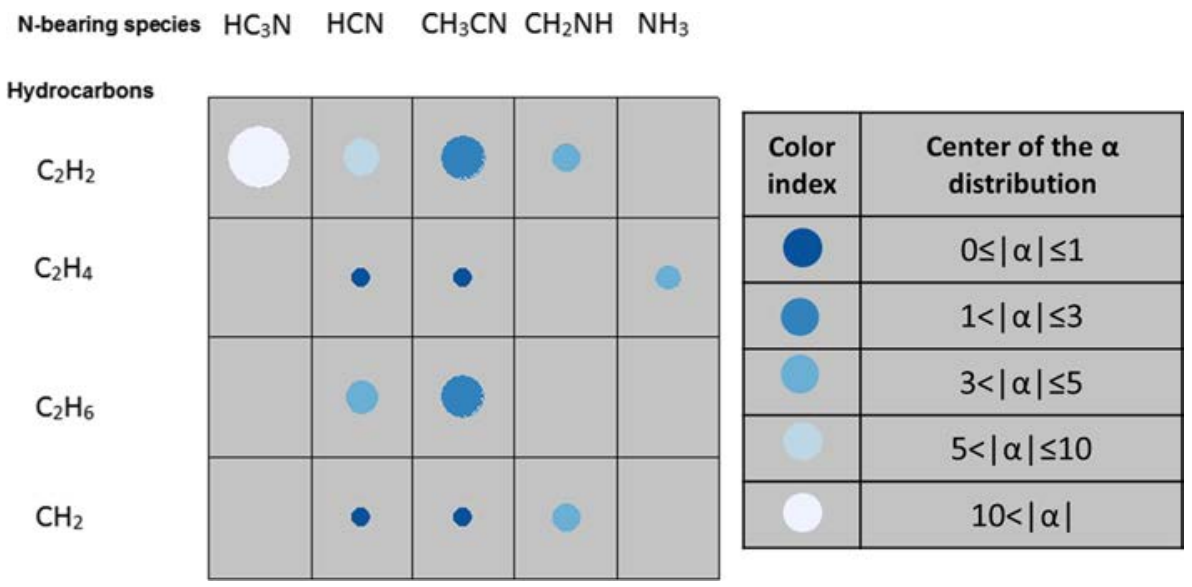

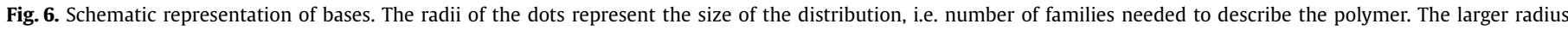

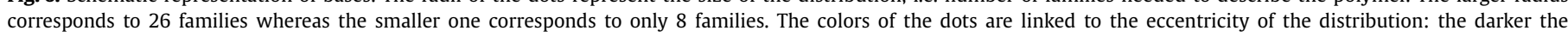

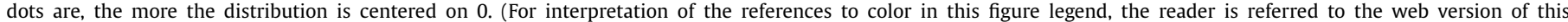
article.)

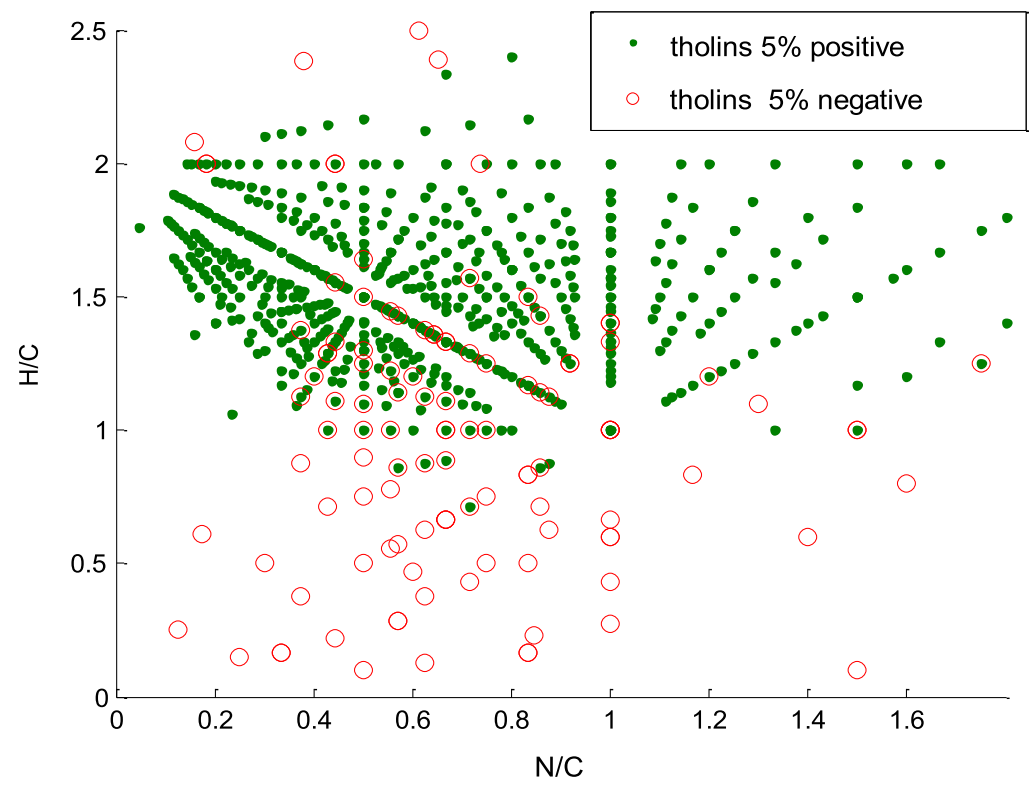

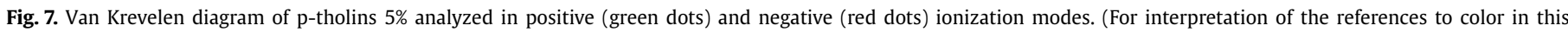
figure legend, the reader is referred to the web version of this article.)

On the choice of the nitrogen bearing pattern, nitriles, and especially $\mathrm{CH}_{3} \mathrm{CN}$ and $\mathrm{HCN}$, provide more parsimonious representations than ammonia, which is a better polymeric base than imines. Looking at distributions and considering stable neutral species, the best possible bases are $\mathrm{HCN} / \mathrm{C}_{2} \mathrm{H}_{4}$ and $\mathrm{CH}_{3} \mathrm{CN} / \mathrm{C}_{2} \mathrm{H}_{4}$. This is fully in agreement with the main chemical species identified in the atmosphere of Titan. Although it was not considered as an exclusion criteria, it is interesting to note here that the convergence point observed in the 3D Van Krevelen diagram corresponds to a C:H:N ratio of $1: 1.5: 0.5$, which is also the ratio found considering $2 \mathrm{HCN}$ $+\mathrm{C}_{2} \mathrm{H}_{4}$ or $\mathrm{HCN}+\mathrm{CH}_{2}$.

\subsection{Comparison of $p$-tholins mass spectra obtained in the positive and negative ionization modes}

Recent work on chemical analyses of p-tholins showed the interest of using the negative ion mode (Somogyi et al., 2012). The comparison between positive and negative ionization modes of p-tholins produced in PAMPRE with $5 \%$ of methane is given in Fig. 7.
As shown in Fig. 7, the molecules detected in the negative ion mode are less numerous (40\% less than in positive ionization mode) and different from the molecules detected in the positive ion mode. The molecules detected in negative mode generally present a lower $\mathrm{H} / \mathrm{C}$ ratio, leading to a higher Double Bond Equivalent (DBE). Positive ionization seems to emphasize the detection of hydrogen rich nitrogenous compounds such as amines, whereas negative ionization mode allows detection of compounds poorer in hydrogen - such as nitriles or cyclic compounds. Both amine and nitrile functions have been detected unambiguously in p-tholins by infrared spectroscopy (Gautier et al., 2012; Imanaka et al., 2004; Quirico et al., 2008). The detection of fewer compounds in the negative ion mode may be connected with the infrared analyses where amine bands are much more predominant in p-tholins spectrum than nitrile bands. This is consistent with an important amine content in p-tholins. The enhancement of nitriles in the negative ionization mode might also be linked to their high electronic affinity (Vuitton et al., 2009). 


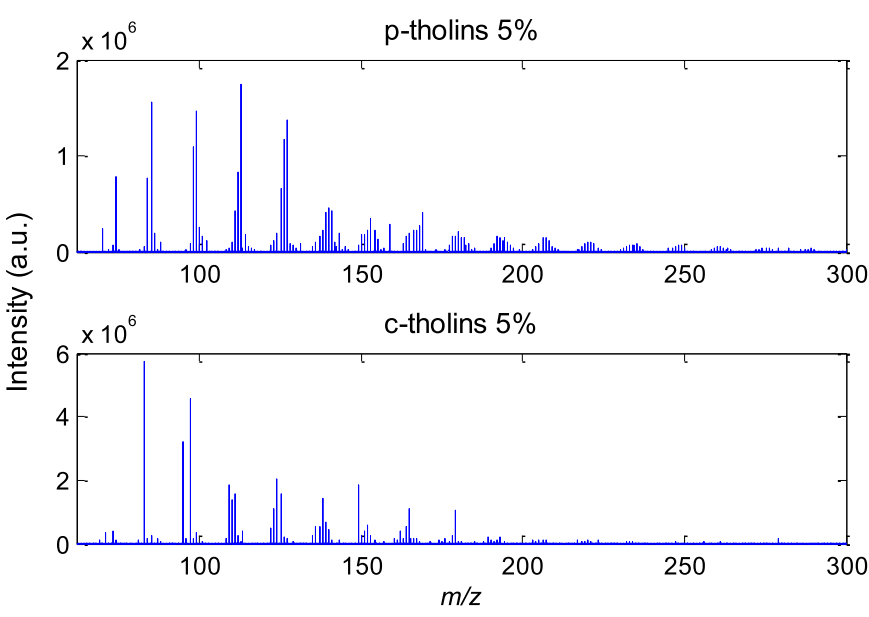

Fig. 8. Orbitrap mass spectra between $m / z 60$ and $m / z 300$ in positive ionization mode of p-tholins and c-tholins samples produced with $5 \%$ of methane.

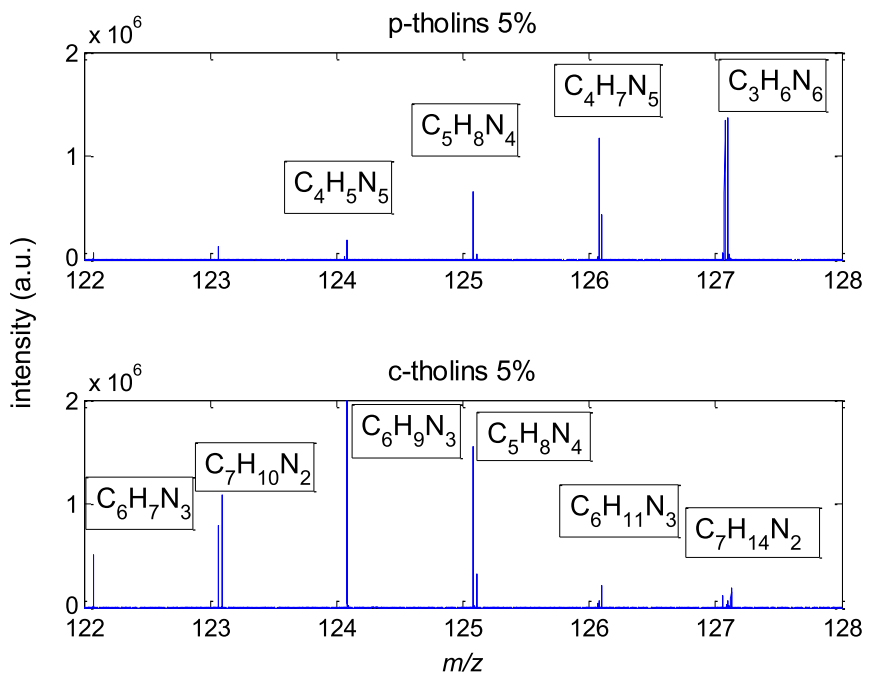

Fig. 9. Close-up of Fig. 9 on the $120-130 \mathrm{~m} / \mathrm{z}$ range. Textbox indicates the predominant peaks in each cluster.

\subsection{Comparison of the composition of p-tholins versus c-tholins}

The mass spectrum of the c-tholins obtained with $5 \%$ of methane is shown in Fig. 8 with the spectrum of p-tholins in the same condition as a reference point. Fig. 9 presents a close-up of Fig. 8. Fig. 9 shows that the distribution of peaks inside clusters is totally different between the two materials. The distribution of peaks in a cluster is systematically shifted toward low masses for the c-tholins compared with p-tholins. This observation is shown in Fig. 9 for the $m / z$ range $120-130$, but it is also observed for the entire spectrum.

It must be noted that all the peaks observed in p-tholins are systematically present in the c-tholins too. This means that Van Krevelen diagram are exactly the same for c-tholins and p-tholins since this representation does not include information on the peak intensities. As for the 2D diagrams, since c-tholins presents similar Van Krevelen diagram than p-tholins, the 3D Van Krevelen diagram of c-tholins also presents this convergence at high masses toward $\mathrm{H} / \mathrm{C}=1.5$ and $\mathrm{N} / \mathrm{C}=0.5$ point.

The dominant peaks in p-tholins are not the dominant ones in the c-tholins. Indeed, the shift of peaks toward low masses (in the same cluster) observed in the c-tholins (see Fig. 9) seems to be due to a larger incorporation of carbon compared to nitrogen in the c-tholins.
It should be noted that both samples were produced at different pressures: 0.9 mbar for p-tholins, 1.7 mbar for c-tholins. Elemental analysis has shown that the pressure effect on the sample chemical composition is weak (Sciamma-O'Brien et al., 2010).

It should also be noticed that a heterogeneous chemistry probably occurs in both cases. In the PAMPRE reactor, heterogeneous chemistry could occur on the surface of p-tholins growing in the gas phase (solid-gas process), whereas in the cold trap, the c-tholins are formed during the melting of condensed icy species, potentially leading to a solid(c-tholins)-liquid chemical process.

The major difference between the samples explaining such a nitrogen depletion in c-tholins is thus the chemical environment of the samples during their production. Indeed p-tholins are produced within a reactive plasma, which includes interaction with electrons and positive/negative ions. On the contrary, their lifetimes preclude ions to reach the cryogenic trap. C-tholins are thus produced in an only a neutral environment. The difference between the samples means that the ion chemistry plays a more important role in the formation of p-tholins, whereas the chemistry generating the c-tholins seems to mainly induce polymerization of carbon rich molecules.

\subsection{C-tholins analysis by GC-MS}

A chromatogram obtained by direct GC-MS analysis of c-tholins is given in Fig. SI 2 ( $a$ and b). As seen in this figure, many peaks in the chromatograms cannot be identified. This is mainly due to the nature of compounds present in tholins-kind materials (mainly nitriles here), which are underrepresented in the databases available for molecular identification.

The list of all compounds identified by direct and derivatization methods is given in Table 1 .

Direct GC-MS analysis allowed identification of ten molecules within c-tholins, all of them being nitrogenized (either bearing amine functional groups or nitrile functional groups or both). However such direct analysis detects only the volatile compounds present in the mixture. After derivatization, the main difficulty for interpreting data comes from the lack of reference in the databases for such $\mathrm{N}$-rich organic compounds. The few peaks identified are mostly highly nitrogenized compounds, mainly nitrile or amines. The detection of alanine and urea in derivatized tholins produced by plasma has also been reported (Ramírez et al., 2010; Hörst et al., 2012).

The molecules detected in c-tholins by GC-MS are consistent with analysis of p-tholins by GC-MS and pyr-GC-MS in the literature, including numerous nitrogen bearing molecules, especially with nitrile functions and nitrogen inclusion within aromatic cycles (Coll et al., 1999; He and Smith, 2013; McGuigan et al., 2006).

C-tholins analysis is also in agreement with the molecules identified in the gas phase in the cryogenic trap connected to a GC-MS (Gautier et al., 2011). The detection of numerous nitrogen bearing molecules including nitrile functional groups confirms the nitrile reactivity as suggested in Gautier et al. (2011). In the present study many molecules bearing amine functions were also detected. This kind of molecule was not observed in the gas phase coming from the cryogenic trap. A possible explanation for this difference is that the gas injected in the GC-MS was transferred from the cryogenic trap through stainless steel connections, where amines can easily adsorb.

The detected molecules present a quite low N/C ratio (compared to orbitrap analysis of c-tholins), but nitrogen atoms are detected within the structure and not only as terminal functional groups, as previously suggested for p-tholins with $\mathrm{C}-\mathrm{N}-\mathrm{C}$ alternation (Carrasco et al., 2009). This emphasizes that nitrogen seems to be essential to initiate the molecular growth. 
Table 1

List of molecules detected using direct injection and after derivatization, their identification in Fig. SI 2 and their formula. Molecules are identified by comparison of their mass spectra with the NIST database.

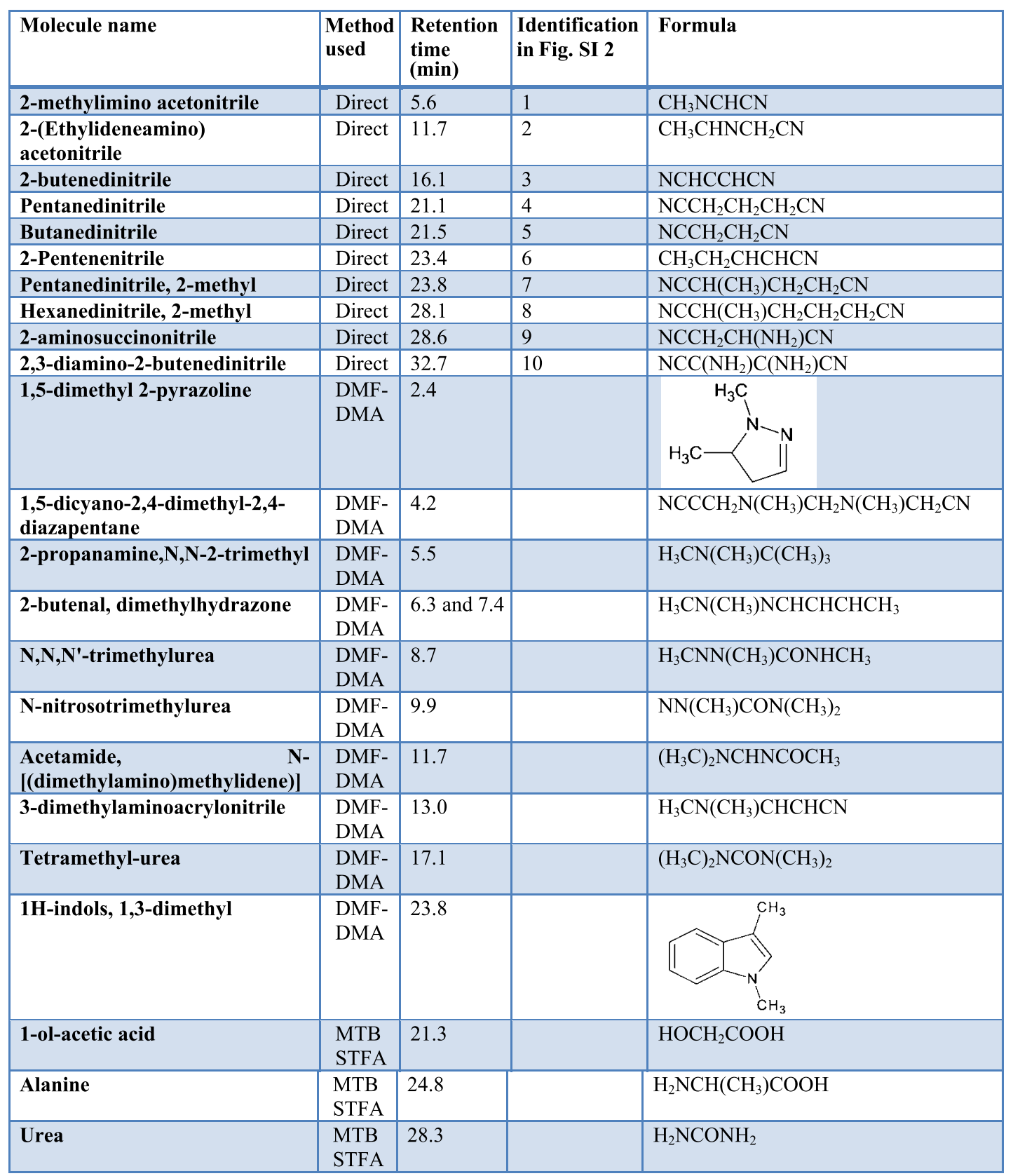

The presence of oxygenated species (whereas no oxygen is introduced in PAMPRE), including amino acids such as alanine is also reported. These oxygenated compounds may be formed by oxidation of c-tholins material, either when samples are harvested and exposed to air or dissolved in methanol before evaporation and derivatization. Even if these compounds are clearly not formed in the gas phase in the PAMPRE reactor, their presence is still interesting for the astrobiological aspect of tholins science. Indeed, even if unwanted, the formation of these compounds did not imply specific manipulations. It could then be possible that such a process occurs naturally on Titan. Studies in the literature show similar behavior for p-tholins in water-ammonia solutions (Neish et al., 2009; Poch et al., 2012).

Finally, all molecules detected with this technique are also observed using ESI-orbitrap mass spectrometry. The identifica- tion by GC-MS of more than twenty molecules in c-tholins allows us to draw a first sketch of the growth processes - as it has been done previously with p-tholins (Carrasco et al., 2009; Coll et al., 1999; He and Smith, 2013; McGuigan et al., 2006; Pernot et al., 2010) - for the 50-150 Da mass range, a particularly important range since the initiation of the growth of the whole material starts there. These first trends only represent a small fraction of the material ( $\sim 20$ molecules detected by GCMS against more than 15000 with orbitrap MS). From this point of view, the improvement of mass spectra databases, especially the inclusion of nitrogen-bearing molecules, would be a great help to complete the identification of compounds detected by GCMS and thus the overall knowledge of c-tholins formation processes. 


\section{Conclusion}

In the present work we study the impact of methane percentage in the gas phase on p-tholins high resolution mass spectra, as initiated in Pernot et al. (2010) with plasma-generated tholins produced in two different conditions ( $2 \%$ and $10 \%$ of methane). P-tholins spectra display polymeric structures which are confirmed by the identification of several polymer families in the material. This supports the fact that p-tholins are copolymer-like materials, probably not linear, but hyper branched copolymer (Klee, 2005). Nevertheless, it seems that at high masses $(m / z>300)$, p-tholins produced with $5 \%$ of methane could be approximated to an average ideal $\left(\mathrm{C}_{2} \mathrm{H}_{3} \mathrm{~N}\right)_{n}$ polymer as shown by the analysis of $2 \mathrm{D}$ and 3D Van Krevelen diagrams.

We also compare high resolution mass spectra of $\mathrm{p}$-tholins and c-tholins. This provides some information on the reactive pathways to tholins formation, emphasizing differences between a material produced by polymerization of neutral gases and a material produced in a reactive plasma. The predominant molecules detected in p-tholins contain more nitrogen than the one detected in c-tholins. We can assume that the main difference between both materials is the ion chemistry involved in p-tholins formation but not in ctholins formation. This means that ion chemistry assists nitrogen incorporation into p-tholins, as opposed to neutral chemistry that leads to molecules with lower $\mathrm{N} / \mathrm{C}$ ratio.

Finally, c-tholins are further analyzed by GC-MS, identifying the structure of about twenty molecules in the $50-150 \mathrm{~m} / \mathrm{z}$ range, the key mass range for polymerization initiation. This primary study highlights some trends in c-tholins growth. Molecules are mainly linear chains, with an N/C ratio decreasing with the chain size. Nitrogen reactivity also seems to be essential for the radical growth since nitrogen is found within the structure and not only as terminal functional groups.

In conclusion, the study presented here helps us to understand the formation processes of Titan's tholins. The analytic and statistical methods we used here could also be of great interest for other highly complex organic compounds of cosmochemical interests such as kerogen or the soluble organic matter in meteorites.

\section{Acknowledgements}

Authors would like to thank Dr. Heather Graham for her help proofreading this article. This work was financially supported by CNRS (PNP and ANR-09-704 JCJC-0038 contract).

\section{Appendix A. Supplementary material}

Supplementary material related to this article can be found online at http://dx.doi.org/10.1016/j.epsl.2014.07.011.

\section{References}

Anderson, C.M., Samuelson, R.E., 2011. Titan's aerosol and stratospheric ice opacities between 18 and $500 \mu \mathrm{m}$ : vertical and spectral characteristics from Cassini CIRS. Icarus 212 (2), 762-778.

Buch, A., Sternberg, R., Szopa, C., Freissinet, C., Garnier, C., Bekri, E.J., Rodier, C. Navarro-González, R., Raulin, F., Cabane, M., Stambouli, M., Glavin, D.P., Mahaffy, P.R., 2009. Development of a gas chromatography compatible Sample Processing System (SPS) for the in-situ analysis of refractory organic matter in Martian soil: preliminary results. Adv. Space Res. 43, 143-151.

Cable, M.L., Hörst, S.M., Hodyss, R., Beauchamp, P.M., Smith, M.A., Willis, P.A., 2012. Titan tholins: simulating Titan organic chemistry in the Cassini-Huygens era Chem. Rev. 112, 1882-1909.

Carrasco, N., Schmitz-Afonso, I., Bonnet, J.-Y., Quirico, E., Thissen, R., Dutuit, O. Bagag, A., Laprévote, O., Buch, A., Giulani, A., Adandé, G., Ouni, F., Hadamcik, E., Szopa, C., Cernogora, G., 2009. Characterization of Titan's tholins: solubility, morphology and molecular structure revisited. J. Phys. Chem. A 113, 11195-11203.
Coll, P., Coscia, D., Smith, N., Gazeau, M.C., Ramírez, S.I., Cernogora, G., Israël, G., Raulin, F., 1999. Experimental laboratory simulation of Titan's atmosphere: aerosols and gas phase. Planet. Space Sci. 47, 1331-1340.

Coll, P. Navarro-González, R., Szopa, C., Poch, O., Ramírez, S.I., Coscia, D., Raulin, F., Cabane, M., Buch, A., Israël, G., 2013. Can laboratory tholins mimic the chemistry producing Titan's aerosols? A review in light of ACP experimental results. Planet. Space Sci. 77, 91-103.

Derenne, S., Coelho, C., Anquetil, C., Szopa, C., Rahman, A.S., McMillan, P.F., Corà, F., Pickard, C.J., Quirico, E., Bonhomme, C., 2012. New insights into the structure and chemistry of Titan's tholins via ${ }^{13} \mathrm{C}$ and ${ }^{15} \mathrm{~N}$ solid state nuclear magnetic resonance spectroscopy. Icarus 221, 844-853.

Freissinet, C., Buch, A., Sternberg, R., Szopa, C., Geffroy-Rodier, C., Jelinek, C., Stambouli, M., 2010. Search for evidence of life in space: analysis of enantiomeric organic molecules by $\mathrm{N}, \mathrm{N}$-dimethylformamide dimethylacetal derivative dependant gas chromatography-mass spectrometry. J. Chromatogr. A 1217, 731-740.

Gautier, T., Carrasco, N., Buch, A., Szopa, C., Sciamma-O’Brien, E., Cernogora, G., 2011. Nitrile gas chemistry in Titan's atmosphere. Icarus 213, 625-635.

Gautier, T., Carrasco, N., Mahjoub, A., Vinatier, S., Giuliani, A., Szopa, C., Anderson, C.M., Correia, J.-J., Dumas, P., Cernogora, G., 2012. Mid- and far-infrared absorption spectroscopy of Titan's aerosols analogues. Icarus 221, 320-327.

Gautier, T., Carrasco, N., Stefanovic, I., Sikimic, B., Cernogora, G., Winter, J., 2014. Methane conversion in a $\mathrm{N}_{2}-\mathrm{CH}_{4}$ radiofrequency discharge. Plasma Process. Polym. 11, 427-481. http://dx.doi.org/10.1002/ppap.201300158.

Hadamcik, E., Renard, J.-B., Mahjoub, A., Gautier, T., Carrasco, N., Cernogora, G., Szopa, C., 2013. Optical properties of analogs of Titan's aerosols produced by dusty plasma. Earth Planets Space 65, 1175-1184

He, C., Lin, G., Smith, M.A., 2012a. NMR identification of hexamethylenetetramine and its precursor in Titan tholins: implications for Titan prebiotic chemistry. Icarus 220, 627-634

He, C., Lin, G., Imanaka, H., Smith, M.A., 2012b. Structural investigation of Titan tholins by solution-state ${ }^{1} \mathrm{H},{ }^{13} \mathrm{C}$, and ${ }^{15} \mathrm{~N}$ NMR: one-dimensional and decoupling experiments. J. Phys. Chem. A 116, 4760-4767.

He, C., Smith, M.A., 2013. Identification of nitrogenous organic species in Titan aerosols analogs: nitrogen fixation routes in early atmospheres. Icarus 226, $33-40$.

Hertkorn, N., Frommberger, M., Witt, M., Koch, B.P., Schmitt-Kopplin, P., Perdue, E.M., 2008. Natural organic matter and the event horizon of mass spectrometry. Anal. Chem. 80, 8908-8919.

Hörst, S.M., Yelle, R.V., Buch, A., Carrasco, N., Cernogora, G., Dutuit, O., Quirico, E. Sciamma-O'Brien, E., Smith, M.A., Somogyi, Á., Szopa, C., Thissen, R., Vuitton, V., 2012. Formation of amino acids and nucleotide bases in a Titan atmosphere simulation experiment. Astrobiology 12, 809-817.

Imanaka, H., Cruikshank, D.P., Khare, B.N., McKay, C.P., 2012. Optical constants of Ti$\tan$ tholins at mid-infrared wavelengths $(2.5-25 \mu \mathrm{m})$ and the possible chemical nature of Titan's haze particles. Icarus 218, 247-261.

Imanaka, H., Khare, B.N., Elsila, J.E., Bakes, E.L.O., McKay, C.P., Cruikshank, D.P., Sugita, S., Matsui, T., Zare, R.N., 2004. Laboratory experiments of Titan tholin formed in cold plasma at various pressures: implications for nitrogen-containing polycyclic aromatic compounds in Titan haze. Icarus 168, 344-366.

Imanaka, H., Smith, M.A., 2007. Role of photoionization in the formation of complex organic molecules in Titan's upper atmosphere. Geophys. Res. Lett. 34, L02204.

Israel, G., Szopa, C., Raulin, F., Cabane, M., Niemann, H.B., Atreya, S.K., Bauer, S.J., Brun, J.F., Chassefiere, E., Coll, P., Conde, E., Coscia, D., Hauchecorne, A., Millian, P., Nguyen, M.J., Owen, T., Riedler, W., Samuelson, R.E., Siguier, J.M., Steller, M., Sternberg, R., Vidal-Madjar, C., 2005. Complex organic matter in Titan's atmospheric aerosols from in situ pyrolysis and analysis. Nature 438, 796-799.

Kaiser, R.I., Mebel, A.M., 2012. On the formation of polyacetylenes and cyanopolyacetylenes in Titan's atmosphere and their role in astrobiology. Chem. Soc. Rev. 41, 5490-5501.

Klee, J., 2005. Review: mass spectrometry of step-growth polymers. Eur. J. Mass Spectrom. 11, 591-610.

Lavvas, P., Griffith, C.A., Yelle, R.V., 2011. Condensation in Titan's atmosphere at the Huygens landing site. Icarus 215 (2), 732-750.

McGuigan, M., Waite, J.H., Imanaka, H., Sacks, R.D., 2006. Analysis of Titan tholin pyrolysis products by comprehensive two-dimensional gas chromatography-timeof-flight mass spectrometry. J. Chromatogr. A 1132, 280-288.

McKay, C.P., Pollack, J.B., Courtin, R., 1991. The greenhouse and antigreenhouse effects on Titan. Science 253, 1118-1121.

Meierhenrich, U., Thiemann, W.H.P., Rosenbauer, H., 2001. Pyrolytic methylation assisted enantioseparation of chiral hydroxycarboxylic acids. J. Anal. Appl. Pyrolysis $60,13-26$.

Neish, C.D., Somogyi, Á., Lunine, J.I., Smith, M.A., 2009. Low temperature hydrolysis of laboratory tholins in ammonia-water solutions: implications for prebiotic chemistry on Titan. Icarus 201, 412-421.

Niemann, H.B., Atreya, S.K., Bauer, S.J., Carignan, G.R., Demick, J.E., Frost, R.L., Gautier, D., Haberman, J.A., Harpold, D.N., Hunten, D.M., Israel, G., Lunine, J.I., Kasprzak, W.T., Owen, T.C., Paulkovich, M., Raulin, F., Raaen, E., Way, S.H., 2005. The abundances of constituents of Titan's atmosphere from the GCMS instrument on the Huygens probe. Nature 438, 779-784.

Pernot, P., Carrasco, N., Thissen, R., Schmitz-Afonso, I., 2010. Tholinomics-chemical analysis of nitrogen-rich polymers. Anal. Chem. 82, 1371-1380. 
Poch, O., Coll, P., Buch, A., Ramírez, S.I., Raulin, F., 2012. Production yields of organics of astrobiological interest from $\mathrm{H}_{2} \mathrm{O}-\mathrm{NH}_{3}$ hydrolysis of Titan's tholins. Planet. Space Sci. 61, 114-123.

Quirico, E., Montagnac, G., Lees, V., McMillan, P.F., Szopa, C., Cernogora, G., Rouzaud, J.-N., Simon, P., Bernard, J.-M., Coll, P., Fray, N., Minard, R.D., Raulin, F., Reynard, B., Schmitt, B., 2008. New experimental constraints on the composition and structure of tholins. Icarus 198, 218-231.

Ramírez, S.I., Coll, P., Buch, A., Brassé, C., Poch, O., Raulin, F., 2010. The fate of aerosols on the surface of Titan. Faraday Discussion 147.

Ruiz-Bermejo, M., Menor-Salván, C., de la Fuente, J.L., Mateo-Martí, E., OsunaEsteban, S., Martín-Gago, J.Á., Veintemillas-Verdaguer, S., 2009. $\mathrm{CH}_{4} / \mathrm{N}_{2} / \mathrm{H}_{2}$-spark hydrophobic tholins: a systematic approach to the characterisation of tholins. Part II. Icarus 204, 672-680.

Ruiz-Bermejo, M., Menor-Salván, C., Mateo-Martí, E., Osuna-Esteban, S., Martín-Gago, J.Á., Veintemillas-Verdaguer, S., 2008. $\mathrm{CH}_{4} / \mathrm{N}_{2} / \mathrm{H}_{2}$ spark hydrophilic tholins: a systematic approach to the characterization of tholins. Icarus 198, 232-241.

Sekine, Y., Imanaka, H., Matsui, T., Khare, B., Bakes, E., McKay, C., Sugita, S., 2008. The role of organic haze in Titan's atmospheric chemistry I. Laboratory investigation on heterogeneous reaction of atomic hydrogen with Titan tholin. Icarus 194, 186-200.
Sciamma-O’Brien, E., Carrasco, N., Szopa, C., Buch, A., Cernogora, G., 2010. Titan's atmosphere: an optimal gas mixture for aerosol production? Icarus 209, 704-714.

Somogyi, Á., Smith, M.A., Vuitton, V., Thissen, R., Komáromi, I., 2012. Chemical ionization in the atmosphere? A model study on negatively charged "exotic" ions generated from Titan's tholins by ultrahigh resolution MS and MS/MS. Int. J. Mass Spectrom. 316-318, 157-163.

Szopa, C., Cernogora, G., Boufendi, L., Correia, J.J., Coll, P., 2006. PAMPRE: a dusty plasma experiment for Titan's tholins production and study. Planet. Space Sci. 54, 394-404

Tran, B.N., Ferris, J.P., Chera, J.J., 2003. The photochemical formation of a Titan haze analog. Structural analysis by X-ray photoelectron and infrared spectroscopy. Icarus 162, 114-124.

Vuitton, V., Lavvas, P., Yelle, R.V., Galand, M., Wellbrock, A., Lewis, G.R., Coates, A.J., Wahlund, J.E., 2009. Negative ion chemistry in Titan's upper atmosphere. Planet. Space Sci. 57, 1558-1572.

Waite, J.H., Young, D.T., Cravens, T.E., Coates, A.J., Crary, F.J., Magee, B., Westlake, J. 2007. The process of tholin formation in Titan's upper atmosphere. Science 316 870-875.

West, R., Lavvas, P., Anderson, C., Imanaka, I., 2014. Titan's Haze. In: Titan. 1st ed. Cambridge University Press, Cambridge, pp. 285-321. 